14

\title{
Незаполненные электронные состояния и потенциальный барьер в пленках замещенных дифенилфталидов на поверхности высокоупорядоченного пиролитического графита
}

\author{
(C) А.С. Комолов ${ }^{1}$, Э.Ф. Лазнева ${ }^{1}$, Н.Б. Герасимова ${ }^{1}$, В.С. Соболев ${ }^{1}$, С.А. Пшеничнюк ${ }^{2}$, \\ Н.Л. Асфрандиаров ${ }^{2}$, В.А. Крайкин ${ }^{3}$, В. Handke ${ }^{4}$
}

${ }^{1}$ Санкт-Петербургский государственный университет,

Санкт-Петербург, Россия

${ }^{2}$ Институт фризики молекул и кристаллов - обособленное структурное подразделение

Уфимского федерального исследовательского центра РАН,

Уфа, Россия

${ }^{3}$ Уфимский институт химии - обособленное структурное подразделение

Уфимского федерального исследовательского центра РАН,

Уфра, Россия

${ }^{4}$ AGH University of Science and Technology.

Faculty of Material Science and Ceramics. Al. Mickiewicza 30,

30-059 Kraków, Poland

E-mail: a.komolov@spbu.ru

Поступила в Редакцию 15 сентября 2020 г.

В окончательной редакции 4 октября 2020 г.

Принята к публикации 5 октября 2020 г.

\begin{abstract}
Приведены результаты исследования незаполненных электронных состояний ультратонких пленок бискарбоксифенил-фталида (DCA-DPP) и бис-метилфенил-фталида (DM-DPP) толщиной до $8 \mathrm{~nm}$. Исследования проводили методом спектроскопии полного тока (TCS) в энергетическом диапазоне от 5 до $20 \mathrm{eV}$ выше $E_{\mathrm{F}}$ в процессе термического вакуумного осаждения этих органических пленок на поверхность высокоупорядоченного пиролитического графита (HOPG). Значения энергии $E_{\mathrm{vac}}$ относительно $E_{\mathrm{F}}$, т. е. электронной работы выхода пленок DM-DPP, при толщине пленки 5-8 nm составили $4.3 \pm 0.1 \mathrm{eV}$. Значения электронной работы выхода пленок DCA-DPP составили $3.7 \pm 0.1 \mathrm{eV}$. Установлена структура максимумов незаполненных электронных состояний пленок DCA-DPP и пленок DM-DPP в исследованном энергетическом диапазоне. Приводится сравнение установленных свойств пленок DCA-DPP и DM-DPP со свойствами пленок молекул незамещенного дифенилфталида (DPP). Так, $-\mathrm{CH}_{3}$ замещение молекулы DPP практически не повлияло на высоту потенциального барьера между пленкой и поверхностью HOPG, a -COOH замещение молекулы DPP привело к увеличению высоты потенциального барьера между пленкой и поверхностью НОРG подложки на $0.5-0.6 \mathrm{eV}$. Замещение молекул DPP функциональными группами -COOH и формирование, таким образом, молекул DCA-DPP привело к сдвигу двух максимумов тонкой структуры спектров полного тока, расположенных при энергиях в диапазоне от 5 до $8 \mathrm{eV}$ выше $E_{\mathrm{F}}$, примерно на $1 \mathrm{eV}$ в сторону меньших энергий электрона.
\end{abstract}

Ключевые слова: фталиды, ультратонкие пленки, высокоупорядоченный пиролитический графит, электронные свойства, низкоэнергетическая электронная спектроскопия, пограничный потенциальный барьер, плотность электронных состояний.

DOI: 10.21883/FTT.2021.02.50483.198

\section{1. Введение}

Полупроводниковые органические пленки на основе молекул фталидов представляют интерес в плане разработки элементов устройств органической электроники с изменяемым типом электропроводности $[1,2]$. Наибольшее внимание заслужили дифенил замещенные молекулы фталидов, что, вероятно, следует связывать с существенным увеличением области Пи-сопряжения в молекуле при таком замещении. Изменение электропроводности в пленках фталидов следует связывать с разрывом ковалентной связи $\mathrm{C}-\mathrm{O}$ в составе пятичленного цикла в молекуле (рис. 1) [3,4]. Это приводит к изменению электропроводности пленок на несколько порядков, что может быть использовано при разработке молекулярных электрических переключателей - современного направления органической электроники [5,6]. Раскрытие пятичленного цикла в молекуле фталида требует определенной энергии активации, несколько десятых долей $\mathrm{eV}$ [7]. Воздействие на электронную систему тонкой пленки сопряженных молекул можно обеспечить путем переноса электронного заряда на границе органического материала и твердотельной поверхности [8-10] или путем введения электроактивных заместителей в молекулу $[11,12]$.

Ранее мы исследовали незаполненные электронные состояния пленок дифенилфталида (DPP - 
Diphenylphthalide) с помощью методик резонансного захвата электронов $[7,13]$ и спектроскопии полного тока (TCS - Total Current Spectroscopy) [14,15]. Были установлены границы максимумов вакантных электронных состояний пленок DPP в энергетическом диапазоне от 5 до $20 \mathrm{eV}$ выше $E_{\mathrm{F}}$ и исследовано формирование потенциального барьера на интерфейсе поверхности подложки высокоупорядоченного пиролитического графита (HOPG - Highly Oriented Pyrolytic Graphite) и пленки DPP. Из литературных данных известно, что поверхность HOPG демонстрирует хорошо воспроизводимые значения электронной работы выхода около $4.6 \mathrm{eV}$ и практически не оказывают влияние на электронную структуру адсорбированных на ней органических молекул [16]. В настоящей работе приведены результаты исследований методом TCS незаполненных электронных состояний зоны проводимости ультратонких пленок $-\mathrm{COOH}$ замещенного и $-\mathrm{CH}_{3}$ замещенного дифенилфталида (рис. 1) и исследований формирования потенциального барьера на границе этих пленок с поверхностью НOPG.

\section{2. Эксперимент}

Для формирования пленок использовали реактивы бис-карбоксифенил-фталида дифенилфталида (DCA-DPP), идентичные реактивам, исследованным в работах $[7,13]$ и бис-метилфенил-фталида (DM-DPP) (рис. 1). Поверхность HOPG подложки получали методом скола в условиях атмосферного давления, затем подложку помещали в вакуумную камеру и проводили дальнейшую очистку ее поверхности воздействием фокусированного пучка Хе лампы высокого давления. Это приводило к нагреву поверхности до $300^{\circ} \mathrm{C}$. Одновременно с подложкой в вакуумную камеру помещали ячейки Кнудсена, заполненные реактивами DCA-DPP и DM-DPP. Обезгаживание реактивов проводили путем выдерживания в вакууме при нагреве до $100^{\circ} \mathrm{C}$ в течение $2-3 \mathrm{~h}$. Базовое давление в камере на стадии подготовки и при проведении экспериментов составляло $10^{-6} \mathrm{~Pa}$.

Термическое осаждение каждой из пленок DCA-DPP и DM-DPP проводили на HOPG подложку, имеющую комнатную температуру. Расстояние от источника органического материала до подложки составляло около $8 \mathrm{~cm}$. Скорость осаждения составляла примерно $0.1 \mathrm{~nm} / \mathrm{min}$, что контролировали с помощью кварцевого резонатора. В процессе осаждения пленок происходило повышение давления в вакуумной камере на порядок от базового давления. Измерения электронных свойств пленок DCA-DPP и DM-DPP на HOPG поверхности проводили методом спектроскопии полного тока (TCS) $[17,18]$ непосредственно в процессе осаждения этих пленок при увеличения толщины органического покрытия до 8-10 nm. При TCS измерениях в процессе осаждения пленок спектральные особенности, исходящие от подложки, затухали, и формировалась новая структура максимумов, отражающая электронные свойства сформированных пленок. B TCS эксперименте падающий

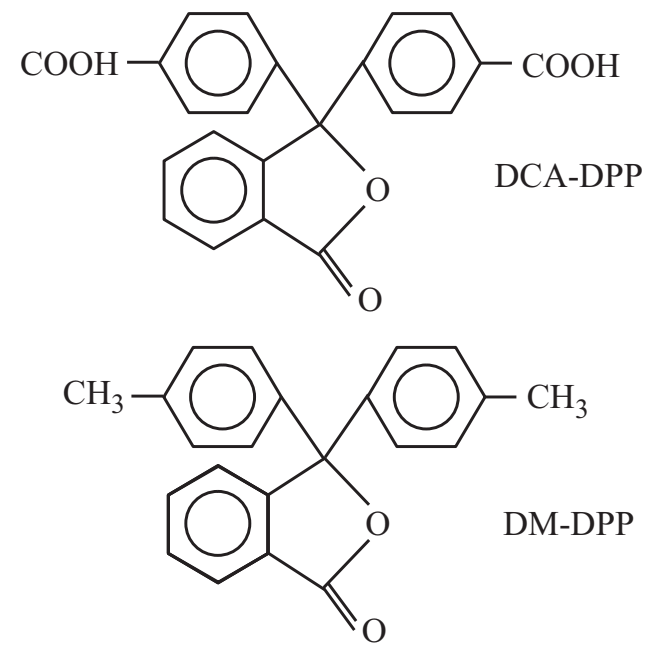

Рис. 1. Структурные формулы молекул бис-карбоксифенилфталида (DCA-DPP) и бис-метилфенил-фталида (DM-DPP).

пучок электронов направляли по нормали к исследуемой поверхности и с помощью lock-in усилителя регистрировали производную по энергии от полного тока $S(E)$, проходящего через образец. Площадь исследуемого участка поверхности составляла $0.2-0.4 \mathrm{~mm}^{2}$. Энергию падающих электронов задавали в диапазоне от 0 до $25 \mathrm{eV}$ относительно уровня вакуума $\left(E_{\mathrm{vac}}\right)$ исследованной поверхности. TCS предоставляет возможность определять работу выхода исследуемой поверхности относительно уровня Ферми системы, то есть величину $\left(E_{\mathrm{vac}}-E_{\mathrm{F}}\right) \mathrm{c}$ учетом калибровки инструмента [17]. Калибровку можно проводить и с использованием поверхности HOPG, которая демонстрирует хорошо воспроизводимые значения электронной работы выхода около $4.6 \mathrm{eV}$ [16], Тонкая структура спектров полного тока (ТССПТ) отражает структуру расположения нижних границ особенностей плотности незаполненных электронных состояний (DOUS - Density of Unoccupied Electronic States) в зоне проводимости $[17,19]$.

\section{3. Результаты и обсуждение}

Формирование потенциального барьера на границе органической пленки и подложки исследовали путем измерения значения $E_{\mathrm{vac}}$ исследованной поверхности относительно $E_{\mathrm{F}}$ в процессе осаждения органического покрытия. Экспериментально регистрировали энергетическое положение первичного TCS-максимума. Оно отражает пороговое значение энергии электронов в падающем пучке, при котором электроны могут достичь исследуемой поверхности. При установлении значения работы выхода целесообразно использовать результаты калибровки TCS инструмента на известных поверхностях. Так для поверхности атомно-чистого $\mathrm{Au}$ значение работы выхода составляет $5.2 \mathrm{eV}$, а для поверхности HOPG - примерно $4.6 \mathrm{eV}$ [16]. Изменение значения $E_{\mathrm{vac}}-E_{\mathrm{F}}$ в процессе формирования интерфейсов 

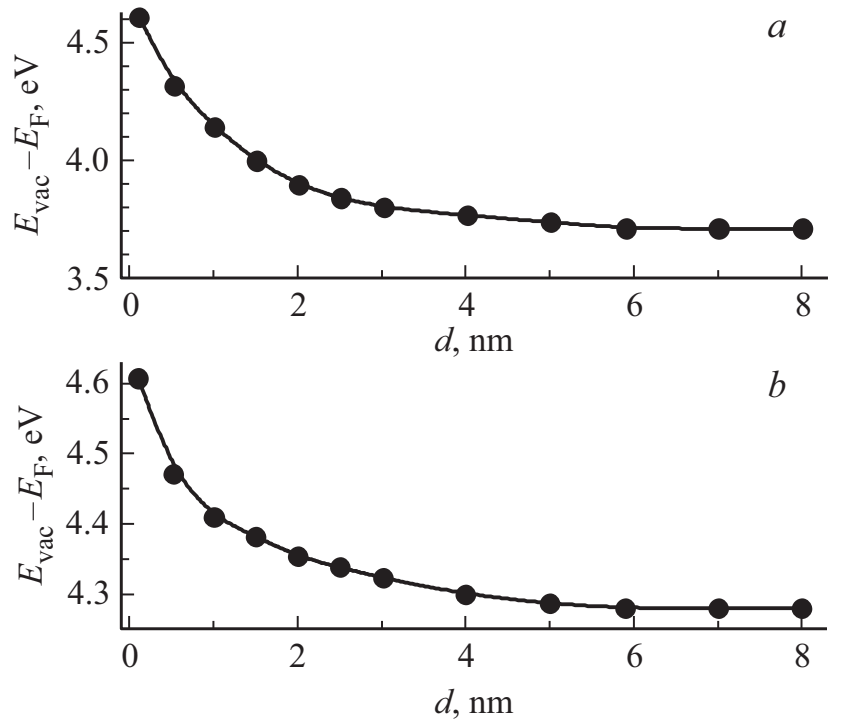

Рис. 2. Анализ энергетического положения первичного TCS-максимума при формировании пленок DCA-DPP и DM-DPP на поверхности HOPG. Изменение положения уровня вакуума $E_{\mathrm{vac}}$ относительно $E_{\mathrm{F}}$ в зависимости от толщины осажденного слоя (a) DCA-DPP и $(b)$ DM-DPP.

HOPG/DCA-DPP и HOPG/DM-DPP показано на рис. 2. При нулевой толщине органического покрытия значение $E_{\mathrm{vac}}-E_{\mathrm{F}}$ поверхности соответствовало работе выхода HOPG подложки и составило приблизительно $4.6 \mathrm{eV}$. Следует принять во внимание, что погрешность определения значений $E_{\mathrm{vac}}-E_{\mathrm{F}}$ составляет $0.1 \mathrm{eV}$ вследствие разброса энергий электронов в падающем тестирующем пучке. При увеличении толщины DCA-DPP пленки до 5-8nm обнаружено снижение работы выхода на $0.9 \mathrm{eV}$, а при осаждении пленки DM-DPP аналогичной толщины снижение работы было менее значительным, $0.3 \mathrm{eV}$ (рис. 2). При этом основное изменение значений работы выхода происходило в слое пленки толщиной $2 \mathrm{~nm}$, а при толщине более $5 \mathrm{~nm}$ положение $E_{\text {vac }}$ поверхности практически не изменялось. Эти наблюдения соответствуют результатам исследований значительного количества интерфейсов сопряженных органических пленок с твердотельными поверхностями [18,20-22], в которых показано, что формирование значения работы выхода происходит в достаточно узком слое пленки, толщиной $1-3 \mathrm{~nm}$. Значения работы выхода пленок DM-DPP (рис. 2,b) составили $4.3 \pm 0.1 \mathrm{eV}$, и они не отличаются от значений работы выхода пленок незамещенного дифенилфталида (DPP), установленных нами ранее [14]. Таким образом, $-\mathrm{CH}_{3}$ замещение молекулы DPP практически не повлияло на высоту потенциального барьера между пленкой и HOPG поверхностью. Значения работы выхода пленок DCA-DPP, т.е. пленок молекул, содержащих - СООН функциональную группу, составили $3.7 \pm 0.1 \mathrm{eV}$ (рис. 2, a). Так, добавление функциональной группы -COOH к молекуле DPP привело к увеличению высоты потенциального барьера между пленкой и поверхностью HOPG подложки на $0.5-0.6 \mathrm{eV}$.
Известно, что одним из методов оптимизации электронных характеристик сопряженных органических пленок является введение в состав молекул поляризующих заместителей. Добавление поляризующих функциональных групп может приводить к изменению значений потенциала ионизации и электронного сродства материала $[11,23]$. При этом введение электрон-притягивающих функциональных групп приводит к стабилизации энергетических уровней в органическом материале, т.е. к понижению их энергетического положения. В случае молекул DCA-DPP квантово-химические расчеты свидетельствуют в пользу стабилизации низколежащих вакантных молекулярных орбиталей в результате влияния карбоксильной функциональной группы [13]. Понижение значений $E_{\mathrm{vac}}-E_{\mathrm{F}}$ при осаждении пленки соответствует избытку положительного заряда в пленке, то есть переносу отрицательного заряда из пленок DM-DPP и DCA-DPP в HOPG подложку. Согласно предположениям, сделанным в работах $[4,7]$, существенное изменение электропроводности материалов на основе молекул фталидов обусловлено разрывом связи $\mathrm{C}-\mathrm{O}$ в составе пятичленного цикла фталида. Одним из условий раскрытия пятичленного цикла фталида является присутствие дополнительного электронного заряда вблизи молекулы фталида, что вытекает из результатов исследований таких пленок методом резонансного захвата электронов молекулами в газовой фазе [7,14]. В исследованных структурах DM-DPP и DCA-DPP на HOPG подложке органическая пленка выступает в роли донора электронов, т. е. отдает электронный заряд HOPG поверхности.

При задании в ходе эксперимента энергии электронов в падающем пучке выше энергии первичного TCS максимума можно наблюдать тонкую структуру спектров полного тока (ТССПТ), т.е. серию максимумов и минимумов, обусловленных различием интенсивности отражения падающих электронов от исследованной поверхности при различных энергиях падающих электронов. Энергетический диапазон для регистрации ТССПТ расположен обычно в пределах от 5 до $25 \mathrm{eV}$ выше $E_{\mathrm{F}}$. Серия ТССПТ, измеренная в процессе осаждения пленок DCA-DPP на поверхность HOPG, представлена на рис. 3. Аналогичным образом, на рис. 4 представлена серия ТССПТ, отражающая формирование пленок DM-DPP на поверхности HOPG. При толщине органического покрытия $0 \mathrm{~nm}$ ТССПТ соответствует поверхности HOPG подложки до нанесения органического покрытия. Наблюдаемая ТССПТ поверхности HOPG имеет ярко выраженный минимум в области $11 \mathrm{eV}$ и максимум в области $19 \mathrm{eV}$ выше $E_{\mathrm{F}}$. Такая ТССПТ достаточно хорошо воспроизводима и наблюдалась нами ранее при исследованиях методом TCS $[14,22]$ и соответствует результатам исследований DOUS поверхности HOPG методом спектроскопии края поглощения рентгеновских лучей (NEXAFS - Near Edge X-ray Absorption Fine Structure) и теоретических расчетов [22,24]. По мере осаждения органических покрытий DCA-DPP и DM-DPP TCCПT подложки затухала, и одновременно нарастала интенсивность новых максимумов ТССПТ, 
которые следует связывать с электронными свойствами этих органических пленок (рис. 3 и 4). Оценку интенсивностей максимумов ТССПТ проводили аналогично методу, рассмотренному в работах $[12,14,17]$. Обнаружено, что появление всех максимумов ТССПТ пленок DCA-DPP и DM-DPP наблюдается на ранней стадии осаждения, когда толщина осажденного слоя еще не достигла $1 \mathrm{~nm}$. Таким образом, молекулы DCA-DPP и DM-DPP, находящиеся в непосредственном контакте c поверхностью подложки, демонстрируют структуру максимумов ТССПТ, аналогичную более толстой пленке. Поэтому следует считать, что взаимодействие на границах HOPG/DCA-DPP и HOPG/DM-DPP не изменяет электронную структуру исследованных молекул, как это наблюдалось и для других интерфейсов органических пленок с подложками малой реакционной способности $[20,21,25]$. При толщине пленок DCA-DPP и DM-DPP примерно $8 \mathrm{~nm}$ интенсивность основных максимумов ТССПТ пришла к насыщению. При увеличении толщины покрытия до 10-12 nm ТССПТ осажденной пленки практически не изменялась как в случае пленок DCA-DPP, так и в случае пленок DM-DPP. А дальнейшее осаждение приводило к размытию максимумов и сдвиг их энергетического положения, связанному с накоплением заряда на поверхности под действием падающего электронного пучка $[11,17]$.

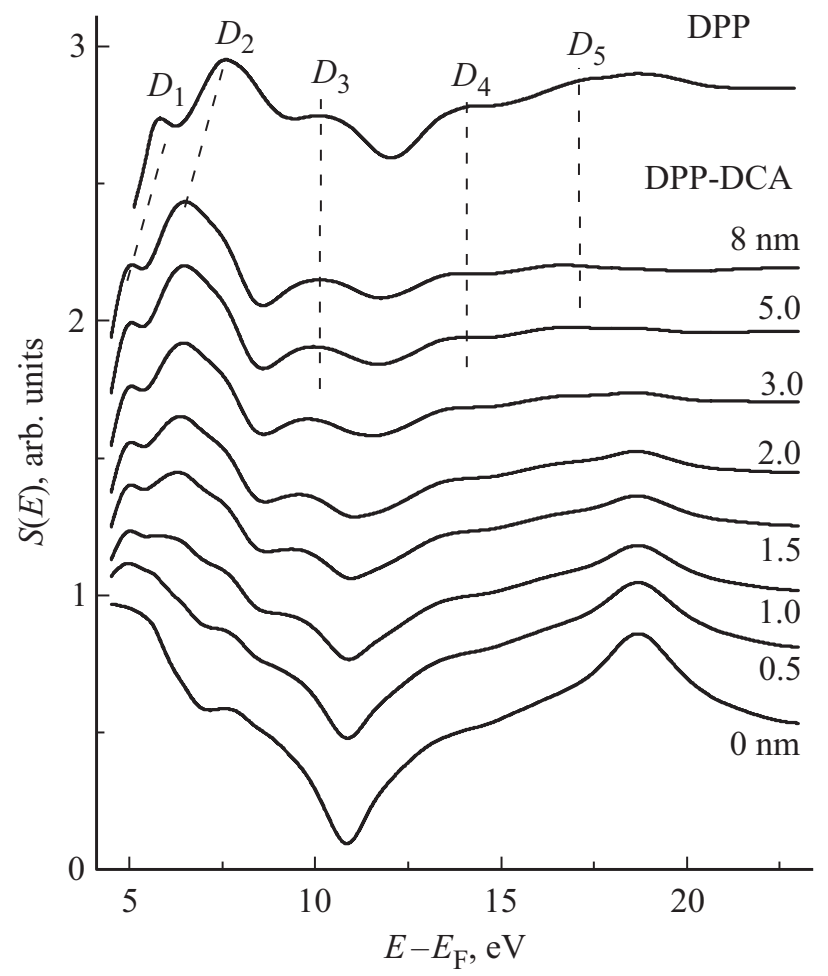

Pис. 3. ТССПТ в процессе осаждения пленок DCA-DPP на поверхность HOPG. Подписи около кривых указывают соответствующую толщину органического покрытия от 0 до $8 \mathrm{~nm}$. В верхней части рисунка приведена ТССПТ пленки незамещенного DPP и указаны максимумы $D_{1}-D_{5}$, характерные пленок DPP. Вертикальные и наклонные штриховые линии показаны для удобства сравнения положений максимумов.

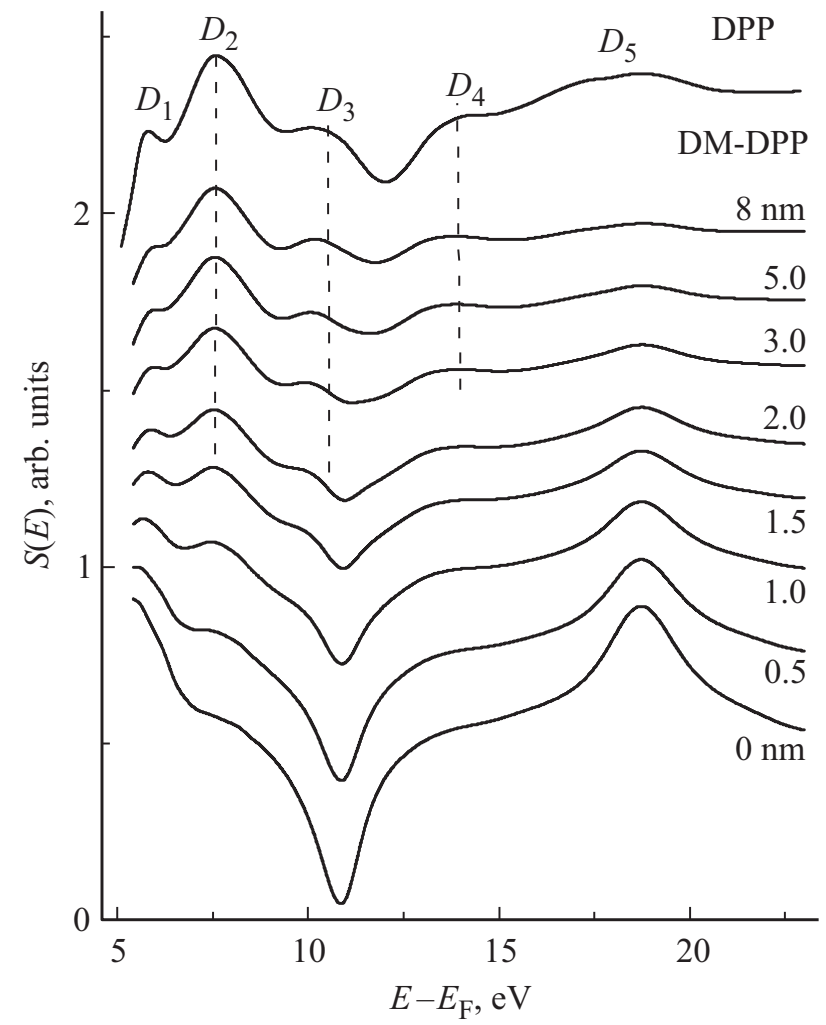

Pис. 4. TCCПT в процессе осаждения пленок DM-DPP на поверхность HOPG. Подписи около кривых указывают соответствующую толщину органического покрытия от 0 до $8 \mathrm{~nm}$. В верхней части рисунка приведена ТССПТ пленки незамещенного DPP и указаны максимумы $D_{1}-D_{5}$, характерные пленок DPP. Вертикальные штриховые линии показаны для удобства сравнения положений максимумов.

Максимумы ТCCПТ пленки DCA-DPP расположены при энергиях $5,6.5,10.5,14$ и $17 \mathrm{eV}$ относительно $E_{\mathrm{F}}$. Положение этих максимумов целесообразно сравнить с положением максимумов ТССПТ пленок незамещенного дифенилфталида (DPP), установленным нами ранее в работе [14] и также представленных на рис. 3. Положение максимумов 10.5, 14 и $17 \mathrm{eV}$ TCCПТ пленки DCA-DPP практически совпадает с положением максимумов $D_{3}-D_{5}$ TCCПТ пленки DPP. Два низкоэнергетических максимума при 5, $6.5 \mathrm{eV}$ сдвинуты относительно соответствующих максимумов $D_{1}$ и $D_{2}$ TCCПT пленки DPP в сторону меньших энергий электрона примерно на $1 \mathrm{eV}$. Было проведено сравнение энергетического положения максимумов TCCПT пленки DM-DPP и максимумов пленки DPP, установленных в работе [14] (рис. 4). Из рис. 4 следует, что расположение максимумов ТССПТ пленки DM-DPP практически не отличается от расположения максимумов $D_{1}-D_{5}$ TCCПТ пленки DPP. Таким образом, $-\mathrm{CH}_{3}$ замещение молекулы DPP практически не повлияло на структуру незаполненных электронных состояний в пленке. Вместе с этим - $\mathrm{COOH} \mathrm{замещение}$ молекул DPP и формирование, таким образом, молекул DCA-DPP привело к сдвигу двух низкоэнергетических максимумов ТССПТ. Установление $\pi^{*}$ или $\sigma^{*}$ характера 
наблюдаемых максимумов ТCCПТ пленок DCA-DPP и DM-DPP было проведено с использованием результатов теоретических расчетов DOUS, представленных в литературе. Так в работе [7] был проведен расчет энергий расположения четырех низколежащих $\pi^{*}$ орбиталей молекул DPP. Для анализа DOUS исследованных пленок было учтено значение энергии поляризации среды в конденсированном состоянии, характерное для полупроводниковых органических материалов $1.2 \mathrm{eV}$ [26]. Из четырех рассчитанных значений энергий максимумов DOUS два расположены ниже энергетического диапазона, охватываемого ТССПТ. Другие два максимума DOUS соответствуют расположению двух низкоэнергетических максимумов ТCCПT пленки DM-DPP (рис. 4). Таким образом, максимумы ТCCПТ в пленках DCA-DPP и DM-DPP при энергиях в диапазоне от 5 до $8 \mathrm{eV}$ можно связать с границами зон $\pi^{*}$ электронных состояний.

\section{4. Заключение}

Методом термического вакуумного осаждения на поверхности HOPG сформированы пленки DCA-DPP и пленок DM-DPP. Установлена структура максимумов незаполненных электронных состояний в энергетическом диапазоне от 5 до $20 \mathrm{eV}$ выше $E_{\mathrm{F}}$ сформированных пленок DM-DPP и пленок DCA-DPP, толщиной до $8 \mathrm{~nm}$ при использовании методики TCS. Замещение молекул DPP функциональными группами - $\mathrm{COOH}$ и формирование, таким образом, молекул DCA-DPP привело к сдвигу двух максимумов ТССПТ, расположенных при энергиях в диапазоне от 5 до $8 \mathrm{eV}$ выше $E_{\mathrm{F}}$, примерно на $1 \mathrm{eV}$ в сторону меньших энергий электрона. Экспериментально установленные значения энергии $E_{\text {vac }}$ относительно $E_{\mathrm{F}}$, то есть электронной работы выхода пленок DM-DPP, при толщине пленки $5-8 \mathrm{~nm}$ составили $4.3 \pm 0.1 \mathrm{eV}$. B случае пленок DCA-DPP значения электронной работы выхода составили $3.7 \pm 0.1 \mathrm{eV}$.

\section{Финансирование работы}

TCS-исследования пленок фталидов выполнены при поддержке гранта Российского научного фонда № 19-13-00021. Диагностика HOPG выполнена при поддержке РФФИ (20-03-00026). В работе использовали оборудование научного парка СПбГУ „Физические методы исследования поверхности“ и „Диагностика функциональных материалов для медицины, фармакологии и наноэлектроники“.

\section{Конфликт интересов}

Авторы заявляют, что у них нет конфликта интересов.

\section{Список литературы}

[1] N. Johansson, A.N. Lachinov, S. Stafstrom, W.R. Salaneck. Synth. Met. 67, 319 (1994).

[2] А.Р. Юсупов, А.Н. Лачинов, Л.Р. Калимуллина, Р.М. Гадиев, Д.В. Никитина. ФТТ 61, 581 (2019).
[3] А.Н. Лачинов, Э.Р. Жданов, Р.Г. Рахмеев, Р.Б. Салихов, В.А. Антипин. ФТТ 52, 181 (2010).

[4] N.L. Asfandiarov, S.A. Pshenichnyuk, A.S. Vorob'ev, E.P. Nafikova, A.N. Lachinov, V.A. Kraikin, A. Modelli. J. Chem. Phys. 142, 174308 (2015).

[5] A.N. Aleshin, P.S. Krylov, A.S. Berestennikov, I.P. Shcherbakov, V.N. Petrov, V.V. Kondratiev, S.N. Eliseeva. Synth. Met. 217, 7 (2016).

[6] П.С. Крылов, А.С. Берестенников, С.А. Фефелов, А.С. Комолов, А.Н. Алешин. ФТТ 58, 2476 (2016).

[7] Н.Л. Асфандиаров, С.А. Пшеничнюк, Р.Г. Рахмеев, А.Н. Лачинов, В.А. Крайкин. ЖТФ 88, 1085 (2018).

[8] A.S. Komolov, E.F. Lazneva, S.N. Akhremtchik. App. Surf. Sci. 256, 2419 (2010).

[9] M. Krzywiecki, L. Grzadziel, P. Powroznik, M. Kwoka, J. Rechmann, A. Erbe. Phys. Chem. Chem. Phys. 20, 16092 (2018).

[10] R.S. Smerdov, A.S. Mustafaev, Y.M. Spivak, V.A. Moshnikov, J. Phys.: Conf. Ser. 1135 (1), 012038 (2018).

[11] A.Y. Sosorev, M.K. Nuraliev, E.V. Feldman, D.R. Maslennikov, O.V. Borshchev, M.S. Skorotetcky, N.M. Surin, M.S. Kazantsev, S.A. Ponomarenko, D.Y. Paraschuk. Phys. Chem. Chem. Phys. 21, 11578 (2019).

[12] A.S. Komolov, E.F. Lazneva, N.B. Gerasimova, Yu.A. Panina, V.S. Sobolev, A.V. Koroleva, S.A. Pshenichnyuk, N.L. Asfandiarov, A. Modelli, B. Handke, O.V. Borshchev, S.A. Ponomarenko. J. Electron Spectr. Rel. Phenom. 235, 40 (2019).

[13] S.A. Pshenichnyuk, A. Modelli, N.L. Asfandiarov, E.F. Lazneva, A.S. Komolov. J. Chem. Phys. 151, 214309 (2019).

[14] А.С. Комолов, Э.Ф. Лазнева, Н.Б. Герасимова, В.С. Соболев, С.А. Пшеничнюк, Н.Л. Асфандиаров, В.А. Крайкин, B. Handke. ФTT 61, 1960 (2019).

[15] А.С. Комолов, Э.Ф. Лазнева, Н.Б. Герасимова, А.В. Барамыгин, В.С. Соболев, С.А. Пшеничнюк, Н.Л. Асфандиаров, B.А. Крайкин, В. Handke. ФТТ 62, 1116 (2020).

[16] J. Hwang, A. Wan, A. Kahn. Mater. Sci. Engineering R 64, 1 (2009).

[17] A.S. Komolov, E.F. Lazneva, S.N. Akhremtchik, N.S. Chepilko, A.A. Gavrikov. J. Phys. Chem. C 117, 24, 12633 (2013).

[18] A.S. Komolov, P.J. Moeller. Appl. Surf. Sci. 244, 573 (2005).

[19] I. Bartos. Progr. Surf. Sci. 59, 197 (1998).

[20] A.L. Shu, W.E. McClain, J. Schwartz, A. Kahn. Organ. Electron. 15, 2360 (2014).

[21] S. Braun, W. Salaneck, M. Fahlman. Adv. Mater. 21, 1450 (2009).

[22] A.S. Komolov, P.J. Moeller. Synth. Met. 138, 119 (2003)

[23] J.-L.Bredas, A.J. Heeger. Chem. Phys. Lett. 217, 507 (1994).

[24] R.A. Rosenberg, P.J. Love, V. Rehn. Phys. Rev. B 33, 4034 (1986).

[25] А.С. Комолов, Э.Ф. Лазнева, Н.Б. Герасимова, Ю.А. Панина, А.В. Барамыгин, Г.Д. Зашихин, С.А. Пшеничнюк. ФТТ 58, 367 (2016).

[26] I.G. Hill, A. Kahn, J. Cornil, D.A. dos Santos, J.L. Bredas. Chem. Phys. Lett. 317, 444 (2000).

Редактор Д.В. Журманов 